\title{
Coulisses
}

Revue de théâtre

10 | Printemps 1994

Varia

\section{Extrait d'un journal de voyage de Corps au Portugal (27 février - 5 mars 1994)}

Catherine Perrin

\section{OpenEdition}

1 Journals

Édition électronique

URL : https://journals.openedition.org/coulisses/3109

DOI : 10.4000/coulisses.3109

ISSN : 2546-9460

Éditeur

Presses universitaires de Franche-Comté

Édition imprimée

Date de publication : 1 juin 1994

Pagination : 77-78

ISSN : 1150-594X

\section{Référence électronique}

Catherine Perrin, «Extrait d'un journal de voyage de Corps au Portugal (27 février - 5 mars 1994) »,

Coulisses [En ligne], 10 | Printemps 1994, mis en ligne le 15 mars 2019, consulté le 28 juin 2022. URL http://journals.openedition.org/coulisses/3109 ; DOI : https://doi.org/10.4000/coulisses.3109

Ce document a été généré automatiquement le 29 septembre 2020.

Coulisses 


\title{
Extrait d'un journal de voyage de Corps au Portugal (27 février - 5 mars 1994)
}

\author{
Catherine Perrin
}

1 Comment exprimer avec les mots les plus justes, des sensations, des impressions, des visages.

Je n'avais aucune idée de ce qu'est le Portugal, de ses habitants, mis à part l'influence latine et les clichés habituels.

Quant aux représentations de CORPS, bien que nous ayons été inégaux dans le jeu, nous avions au moins un avantage, c'est que l'obstacle de la compréhension de la langue n'existait pas. CORPS est pour le moins universel et contemporain, d'autant plus que les images reçues jusqu'alors par des spectateurs complètement différents ont toujours trouvé une résonance. Je refuse d'admettre, comme je l'ai entendu dire, que CORPS est un spectacle élitiste. Donc, je n'avais guère de crainte pour l'accueil du spectacle.

2 Nous sommes donc partis le dimanche 27 février à $6 \mathrm{~h} 30$. Les départs dans les petits matins sont toujours émouvants. Les accessoires s'empilent avec les sacs dans les soutes. Et chacun trouve sa place dans le car, avec tout près de soi, le ravitaillement en tout genre nécessaire pour plus de 24 heures de route!

La traversée de l'Espagne, avec le recul me laisse une drôle d'impression. Ce fut une longue nuit de péages en péages, d'autoroutes gigantesques de villes où se dressaient des cubes de bétons, d'apparitions de militaires cagoulés et armés.

La nuit rend toujours les choses plus impressionnantes, peut-être?

Et sur des routes cahotantes, traversant des petits villages de montagne où s'affairaient au petit jour des écoliers, des femmes, on croisait des cars d'un autre âge.

C'était lundi. Et on allait arriver à Braga, capitale de la région du Minho, au nord-ouest du pays. Braga m'a dit Paula, l'étudiante qui nous hébergeait, est la ville d'Europe où les jeunes sont les plus nombreux.

Le mardi $1^{\circ}$ mars fut celui de la représentation à Braga ; on a investi le théâtre en début d'après-midi. De l'extérieur, coincé dans un pâté de maison de la rue principale de 
Braga, il ne paie pas de mine; par contre, l'intérieur ne manque pas de charme, ses coulisses, ses salles de spectacles, ses couloirs et je suis tombée amoureuse de ses loges, peintures ocres écaillées, avec des miroirs et des coiffeuses que l'on aimerait voir chez soi. L'espace d'une journée, tout cela nous a appartenu. Le soir vit des gens heureux d'avoir assisté au spectacle de CORPS.

4 Le vendredi fut laborieux, cela a commencé par le départ de Braga, puis l'arrivée à Porto où le Théâtre Universitaire, perché dans des espèces de forteresses, était inaccessible au bus. CORPS fut ce soir-là à l'apogée. Le départ après le spectacle fut silencieux, - corps terrassés. La journée du retour était hors de la réalité, somnambulique. Le retour des « morts vivants ».

6 Je garde du Portugal le goût de la générosité des gens, la discrétion d'un pays et de ses habitants.

7 Braga est une ville qui m'a particulièrement séduite, entre le rural et le citadin, entre le passéisme et le modernisme, mais elle me semble encore un peu protégée. Illusion peut-être. En tous les cas, il y fait bon.

Je garde aussi le souvenir d'une discussion avec trois étudiantes sur l'Europe, l'histoire $\mathrm{du}$ Portugal, leurs espoirs politiques et leur militantisme, leurs exigences pour l'avenir de leur pays et d'elles-mêmes. Un échange de ce genre, cette envie que nous avions de mieux connaître de part et d'autre nos histoires, nos cultures, et de prononcer des souhaits pour l'avenir, qui étaient loin d'être différents, c'est peut-être ça une idée de l'Europe.

8 A la croisée de deux chemins, tous les soirs une bougie était allumée dans une vieille lanterne; par qui ? Pour quoi ? Peu importe. Mais quand je rentrais chez Paula, je savais que je m'étais perdue et qu'il fallait prendre la rue la plus à gauche.

9 CORPS ne peut laisser personne intact. 